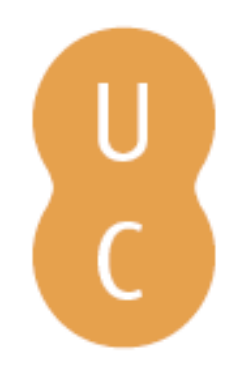

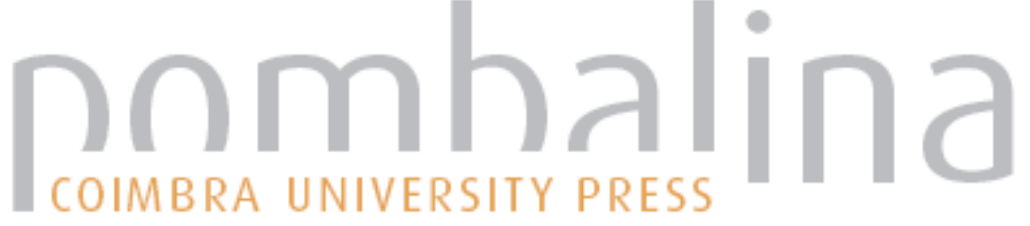

\section{Uma leitura analítica do manuscrito clássico de Karl Marx}

Autor(es): $\quad$ Furtado, Edna Maria

Publicado por: Imprensa da Universidade de Coimbra

URL

persistente: URI:http://hdl.handle.net/10316.2/43538

DOI: $\quad$ DOI:https://doi.org/10.14195/978-989-26-1343-7_40

Accessed : $\quad$ 26-Apr-2023 13:53:06

A navegação consulta e descarregamento dos títulos inseridos nas Bibliotecas Digitais UC Digitalis, UC Pombalina e UC Impactum, pressupõem a aceitação plena e sem reservas dos Termos e Condições de Uso destas Bibliotecas Digitais, disponíveis em https://digitalis.uc.pt/pt-pt/termos.

Conforme exposto nos referidos Termos e Condições de Uso, o descarregamento de títulos de acesso restrito requer uma licença válida de autorização devendo o utilizador aceder ao(s) documento(s) a partir de um endereço de IP da instituição detentora da supramencionada licença.

Ao utilizador é apenas permitido o descarregamento para uso pessoal, pelo que o emprego do(s) título(s) descarregado(s) para outro fim, designadamente comercial, carece de autorização do respetivo autor ou editor da obra.

Na medida em que todas as obras da UC Digitalis se encontram protegidas pelo Código do Direito de Autor e Direitos Conexos e demais legislação aplicável, toda a cópia, parcial ou total, deste documento, nos casos em que é legalmente admitida, deverá conter ou fazer-se acompanhar por este aviso.

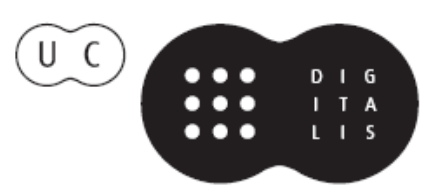




\section{FERNANDA CRAVIDÃO}

\section{IÚCIO CUNHA}

PAULA SANTANA

\section{NORBERTOSANTOS}

(ORG.)

\section{ESPAÇOS E TEMPOS EM GEOGRAFIA}

HOMENAGEM A ANTÓNIO GAMA

IMPRENISA DÁ UNIVERSIDADE DE COIMBRA COIMBRA UNIVERSITY PRESS

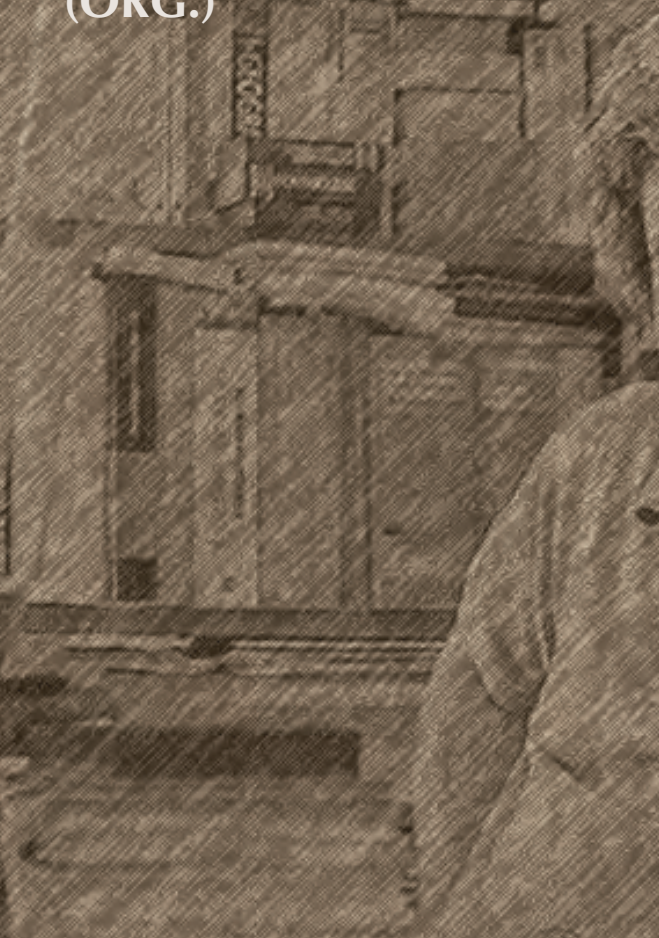




\title{
UMA LEITURA ANALÍTICA DO MANUSCRITO CLÁSSICO DE KARL MARX
}

\author{
Edna Maria Furtado/ed.furtado@hotmail.com \\ Departamento de Geografia \\ da Universidade Federal do Rio Grande do Norte
}

\section{Introduçáo}

Ler os manuscritos económicos-filosóficos buscando desvendar seu conteúdo, ou, mais que isto, produzir sentidos através deles, significa decompô-los de modo a torná-los compreensíveis segundo todo um contexto socio-histórico em que foram elaborados. Em assim sendo, compete reportarmo-nos a uma diacronia, sobretudo marcada por aspectos caracterizadores da juventude de Marx, entre os anos de 1844 a 1853.

Com sua publicação datada de 1932, em formato de ensaio, os manuscritos se constituíram na primeira formulação teórica de Karl Marx sobre a teoria econômica, e compreendem o entendimento das condiçóes de vida da classe operária das indústrias inglesas nos primeiros anos do século xIx, cujos problemas devem ser vistos à luz dos contornos históricos de entáo.

Este artigo propõe-se fazer uma breve discussão sobre a dimensão subjetiva nessa obra intitulada Manuscritos Económico-Filosóficos, a qual trouxe importantes contribuiçôes ao restante da obra de Karl Marx, mas também possibilitou o enriquecimento teórico dos seus seguidores, através das primeiras discussôes sobre importantes categorias de análise das ciências sociais. 
Este trabalho se desdobra em uma pequena apresentação, para então prosseguir no esforço teórico e analítico sobre a subjetividade nos manuscritos e, então, finalizar com algumas consideraçóes, que soam muito mais como novas provocaçóes do que propriamente como conclusões.

\section{Breve contribuição analítica}

$\mathrm{Na}$ verdade, a época de redação desse manuscrito coincide com a época da burguesia triunfante, trazendo a instauração de Luis Felipe ao trono Francês e a consolidação da independência belga, gozando, todo o Ocidente europeu, os benefícios da monarquia constitucional.

No âmbito da filosofia, os manuscritos marcaram o momento em que ele consolida a ruptura com o idealismo de Hegel, sem, no entanto, refutar a negação enquanto princípio fundamental do movimento dialético. Nesse sentido, convém dizer que a evolução do pensamento econômico marxiano é inseparável da elaboração da teoria do materialismo histórico.

Eis que aí a obra de Marx se inscreve, inspirada em Engels, cujas ideias nortearam as críticas daquele sobre a ciência social, que até então fora constituído e ricamente desenvolvido por um pensamento eminentemente burguês. Desse modo, os manuscritos vêm exercer importante papel nas sociedades do ocidente, não obstante se traduza enquanto um conjunto de ideias consubstanciadas de uma das fases de desenvolvimento da produção científica de Marx. Trata-se do emprego de uma forma filosófica de expressão, em função de um empenho em criticar um modo de pensamento igualmente filosófico, vindo a caracterizar um movimento de "[...] transição da disputa filosófica sobre a natureza do homem ou do desenvolvimento social do homem como totalidade, para o estudo empírico dos modernos problemas econômicos e políticos" (Fromm, 1996: 27).

Nessa perspectiva, a obra enfoca a teoria do valor-trabalho enquanto princípio explicativo original para a dominação da propriedade privada, a partir da qual a submissão do proletariado - como processo de alienação - é abordada. 
Com isso, Marx recusa o pensamento de Smith e Ricardo, por concebê-lo inadequado para servir de base a uma ciência política, uma vez que o mesmo se revestia de um aspecto anti-humano e desagregador.

Conforme se vê, a alienaçáo se constitui no conceito-chave dos manuscritos, através do que Marx faz observações de valor empírico acerca do trabalho produtivo, enquanto elemento da saúde mental e da felicidade do indivíduo, utilizando para isso a descrição da situação real do trabalhador na então sociedade industrial. Aqui ele se coloca como humanista, apregoando que o Ser Humano é, em larga medida, determinado pelo modo de vida. E acrescenta que as mudanças pressupooem modificações nas/das circunstâncias que o aprisionam. Isso significa que Marx apoia-se numa doutrina moral e, em ambas as fases, - seja realçando a intensidade da esfera do trabalho, ou entáo do lazer -, apresenta simultânea concepção ideal de indivíduo, quando a ele se refere como um todo desabrochado que livremente exprime sua natureza na atividade.

Como contraponto - e corroborando o que fora dito - ele apresenta a propriedade privada enquanto geradora da criaçáo de riqueza pelos operários que, por sua vez, deles fora expropriada e convertida em capital ou no instrumento de continuada subjugaçáo daqueles que o produziram nele, exteriorizando sua essência humana.

Em seus Manuscritos Económico-filosóficos - obra esta em estudo - Marx esboça uma concepçáa humanista do comunismo, influenciada pela filosofia de Feuerbach ${ }^{1}$, com base num contraste entre a natureza alienada do trabalho no capitalismo e uma sociedade capitalista, na qual os seres humanos desenvolveriam livremente sua natureza em produçáo cooperativa. Com essa obra, a contribuição de Marx para a nossa compreensão da sociedade, foi imensa. Sua grande e central contribuiçáo para a filosofia, e da qual vai derivar o conjunto de sua obra teórica, foi o seu método, o método dialético materialista. Embora o texto em estudo trate especificamente da economia política, é suficientemente preciso para se prestar à generalização, quando considerado no conjunto da

\footnotetext{
${ }^{1}$ Filosofo materialista, em cuja doutrina apregoava a religiáo enquanto projeçấo dos desejos humanos e alienação, vindo posteriormente a influenciar fortemente Marx e Engels.
} 
obra de Marx, e, sobretudo, nos procedimentos que adotou na observaçáo, consideraçáo e teorizaçáo do sistema econômico do capitalismo, de que os manuscritos de 1857 se constituem. Era a manifestaçấo do método científico e correto da elaboração científica.

O procedimento de Marx no tratamento da questáo - em que ele se coloca em perspectiva original - é poder-se dizer revolucionário no campo da filosofia. Ele procura inspirar-se e fundamentar seu método na observação, tornando-o fruto de um método caracterizado que conduzirá, em plena consciência de seus procedimentos, o caminho da elaboração da teoria dos sistemas. E este tem como fontes o materialismo francês do século xvII, a filosofia idealista alemã (de Hegel) e a economia política inglesa do início do século xIx.

Em seus níveis de análise encontram-se o pensamento de Hegel, de Feuerbach (seu discípulo), o qual reformulou o pensamento hegeliano de que o desenvolvimento da história confundia-se com o florescimento da ideia, representaçáo da divindade panteísta, alma do mundo, afirmando que o reino da ideia é substituído pelo reino do homem. O materialismo mecanicista de Feuerbach, pautado sobre o naturalismo, foi ultrapassado por Marx, para o qual o homem criara o Estado, a pátria, a propriedade, o capital, e a todos estes se alienando. Significa que a alienação econômica, política e social corresponderia, socialmente, à alienação religiosa defendida por Feuerbach (para quem o homem criara Deus). Era uma situação que refletia diretamente o estado social vivenciado em um momento dado, qual fosse a projeção no pensamento das relações materiais de dominação.

Nos manuscritos aparecem juntos, pela primeira vez, embora ainda não unidos, o que Engels descreveu como sendo os três elementos constituintes do pensamento de Marx - filosofia idealista alemá, socialismo francês e economia inglesa. Daí a importância da sua leitura para a compreensão do pensamento marxista.

Dos manuscritos, apenas quatro sobreviveram. Os primeiros são textos fragmentados sobre economistas clássicos sobre salário, lucro e renda e notas sobre o trabalho alienado. O segundo é uma pequena análise da relação capital-trabalho. Já o terceiro compreende uma discussáo sobre propriedade privada, 
trabalho e comunismo, crítica da dialética de Hegel, uma seção sobre a produção e divisão do trabalho e breve nota sobre o dinheiro. O quarto é uma análise sobre a fenomenologia do espírito de Hegel.

Sobre a alienação em Marx, ele transfere o centro da questáo - como é vista em Hegel e Feuerbach - para a base concreta, situando-a ao nível da condição material do homem em sua relação com o produto do seu trabalho. Uma relação de estranhamento atestada pela presença da propriedade privada e, consequentemente, da divisão do trabalho, faz com que o homem seja despojado da apreensão da totalidade de seu produto final, dentro do ramo de produção.

Com relação ao trabalho, a definição do Ser pelo marxismo se dá pela interconexão que ele faz entre o indivíduo e a produção. Aquilo que os indivíduos são depende das condiçóes materiais da sua produção. O indivíduo passa a ser visto como simples apêndice de um complexo mecânico em uma produção econômica. Suas demais dimensões, como o pensar e o criar autônomos são isolados.

No que tange ao dinheiro, Marx coloca que, enquanto elemento configurador da propriedade de comprar tudo e de apropriar objetos para si mesmo, esse elemento (o dinheiro) tem, por conseguinte, a característica de se constituir - por excelência - em objeto. Em seu caráter universal de propriedade, ele se reveste de um status de onipotência, soberania, poder e força pela qual todos os impossíveis podem se converter possíveis - aí incluídas as virtudes no seu contrário - o não-ser em ser. Nas próprias palavras de Marx, posto que o dinheiro, como conceito existente e ativo do valor, confunde e troca tudo, ele é a confusão e transposição universais de todas as coisas, o mundo invertido; a confusão e a transposição de todas as qualidades naturais e humanas. Significa, conforme o autor, apud Fromm (1996: 230), que: "o dinheiro, em virtude da propriedade de tudo comprar, de se apropriar de todos os objectos, é, por conseguinte, o objecto por excelência. A universalidade da sua propriedade é a onipotência da sua natureza; considera-se, portanto, como omnipotente (...) o dinheiro é o alcoviteiro entre a necessidade e o objecto, entre a vida do homem e os meios de subsistência. Mas o que mediatiza a minha vida mediatiza igualmente para mim a existência de outros homens. É para mim a outra pessoa”. 
Veja-se que, nessa inversão de valores, recheada de uma (con)fusão de atribuiçóes, tal afirmativa de Marx encerra as análises por ele empreendidas sobre a função do dinheiro na sociedade, segundo a lógica conduzida pela sociedade moderna. Para ele, o patrão de todas as coisas é o deus-dinheiro, e não o homem; aquele "consagrado" pelo mundo burguês como verdadeira e única divindade; bem supremo, que se configura como a verdadeira inteligência.

Contraditoriamente, a subjetividade anula-se perante a materialidade do dinheiro. Por conseguinte, ocorre, paradoxalmente, uma subjetivação - substituidora da humanidade - dos elementos que fazem a composição da estrutura capitalista de produção da existência. Nesse sentido: " [...] o que para mim existe através do dinheiro, aquilo que eu posso pagar, isto é, o que o dinheiro pode comprar, sou eu, o próprio possuidor do dinheiro. O poder do dinheiro é meu próprio poder. As propriedades do dinheiro são as minhas - do possuidor - próprias propriedades e faculdades. Aquilo que eu sou e posso náo é, pois, de modo algum determinado pela minha própria individualidade" (Marx apud Fromm, 1996: 232).

Pode-se constatar ainda, a propósito das reflexóes marxianas expressas nos Manuscritos Económico-Filosóficos, uma propriedade de onipresença atribuída ao dinheiro, quando este vai substituir ou neutralizar todos os limites e debilidades que poderão contaminar o Ser Humano. Em assim sendo, ele passa a constituir-se num "espírito real" - conforme quer o próprio Marx (Marx apud Fromm, 1996) -, como a tomar posse das prerrogativas divinas, conferindo ao seu possuidor todos os desejos subjetivados na condição humana, igualmente conferindo-lhe semelhante ostentação.

Sabe-se que o pensamento de Marx é (re)conhecido como aquele cuja proposta era de inversão da tradiçáo idealista, culminada com Hegel. Nessa perspectiva, ele se insere entre os padróes do método objetivo e científico clássico, reconhecido como materialista, cuja construção teórico-metodológica é o materialismo histórico-dialético.

No entanto, há de se reconhecer, nas entrelinhas de suas proposiçôes - especificamente nos Manuscritos Econômico-Filosóficos - muitos elementos conceituais e linguísticos denunciadores da subjetividade humana, a exemplo de "amargura... 
luta... penúria, sofrimento... desejo... dificuldades... sorte... capricho" (Marx, apud Fromm, 1996: 106). Trata-se de expressóes semanticamente carregadas, que marcam e demarcam um clima de contradição nas relaçóes capitalistas de produção, em que as oposiçóes entre trabalho e capital vêm afirmar uma relação de desigualdade e descompasso entre os que se vendem como produto/ mercadoria e aquele que compra, o detentor da propriedade privada - o capital.

Segundo o pensamento de Marx apud Fromm (1996: 102-103): "O trabalhador tornou-se uma mercadoria e terá muita sorte se puder encontrar um comprador. E a procura, de que depende a vida do trabalhador, é determinada pelo capricho dos ricos e dos capitalistas (...) o trabalhador, portanto, perde mais e perde inevitavelmente com a gravitação do preço corrente para o preço natural. Ao mesmo tempo, é a habilidade do capitalista para dar ao capital outras utilizaçóes que ou condena o trabalhador (limitado a um só emprego do respectivo trabalho) à fome ou a força a sujeitar-se a todas as exigências do capitalismo (...) outra desvantagem do trabalhador: as categorias de salários dos diferentes tipos de trabalhadores variam muito mais do que os lucros nos diversos ramos em que o capital é empregue. No trabalho, todas as diferenças naturais, culturais e sociais da actividade individual aparecem e são remuneradas de modo diverso, enquanto o capital inerte mantém um rendimento invariável e é indiferente à actividade individual real".

Nesse sentido, relevante se faz enunciar, igualmente, noçôes conceituais propostas pelo referido autor, em cujos significados e sentidos estáo presentes estados espirituais, ou de ânimo, que entrelaçam os conteúdos objetivos no campo da economia política.

Assim, ao referir-se ao fenómeno da alienação, peculiar ao modo de produção capitalista, Marx se reporta ao não-usufruto do produto do trabalho humano, uma vez que o trabalhador produz os objetos e as coisas que são transformadas em mercadorias, as quais não podem ser estruturalmente por ele consumidas. Significa que, na medida em que ele é destituído do produto de seu próprio trabalho, torna-se estranho, vindo assim a configurar-se como "[...] tanto mais impotente, quanto mais servo da natureza [...]" (Marx apud Fromm, 1996: 161). 
Conforme o próprio Marx (1988: 5), trata-se da açáo pela qual - ou estado no qual um indivíduo se torna alheio aos resultados do produto de seu trabalho, ou, de sua atividade - e à atividade ela mesma e/ou à natureza na qual viveu, ou ainda a si mesmo, em suas possibilidades humanas constituídas historicamente. É a alienação descrita nos manuscritos, cuja revelação se dá não apenas no fato de que "[...] os meus meios de vida pertencem a outrem; de que meus desejos são a posse inatingível de outro, mas de que tudo é algo diferente de si mesmo, de que minha atividade é qualquer outra coisa e que um poder inumano impera [sobretudo] sobre tudo" (Marx apud Fromm, 1996: 217).

Nesse sentido, pode-se ainda referir-se a tal noçáo conceitual numa dimensão espiritual - não caindo na equivocada compreensão compartimentalizadora e dicotômica entre a dimensão subjetiva e objetiva do homem - a assim chamada alienaçáo fruto de uma visão de mundo originária da propriedade privada e do capitalismo, igualmente disseminada e veiculada pelos institutos educativos ${ }^{2}$, latu sensu, já que, juntamente com os meios de comunicação de massa, encarregam-se de divulgar a ideologia e os interesses da classe proprietária e dominante.

Desse modo, o trabalhador recebe tais ideias e as incorpora, passando a ter uma consciência alienada a sua condição de classe, figurando, portanto, como um estranho alienígena, em sua própria classe de comerciantes de si mesmos para sobreviver.

A ideologia veiculada pelos canais do poder dominante é inculcada nos homens e por eles incorporada, de modo consciente e inconsciente, cujos efeitos são percebidos no estágio de negação total de uma possibilidade objetiva de reação à condição de escravos na qual vivem. Assim: "[...] quanto mais querem ganhar mais tem de sacrificar o tempo e realizar um trabalho escravo em que sua liberdade se encontra totalmente alienada a serviço da avareza. E assim encurtam as suas vidas." (Marx apud Fromm, 1996: 104).

\footnotetext{
2 Sabe-se que todas as Instituiçóes Sociais são consideradas mediadoras do processo de socialização, exercendo portanto o ato educativo no sentido amplo do termo.
} 
É, pois, perante as sobre-referidas contradiçóes, que a oposição estrutural entre o proprietário privado e o comerciante do seu corpo se estreita, revelando e desvelando a essência e a natureza de um modo de vida e de relação social específicos - o capitalismo.

Evidenciam-se tais efeitos, na absorção, sem critérios, dos objetos vendidos através da propaganda e da publicidade, aqueles não dispondo - às vezes - da mínima qualidade consumível. Tais produtos são vendidos e divulgados, porque são colocados pela mídia como objetos de desejo necessários à felicidade de seus consumidores, vindo assim a corroborar o cumprimento do papel do poder econômico e, ao mesmo tempo, aliviar as tensôes provocadas pela infelicidade estrutural a que são relegados os desagregados desse poder.

É possível ainda enumerar outro conceito elaborado por Karl Marx, qual seja o denominado fetichização. Esse conceito é a tradução de um processo de encantamento que os objetos produzidos - a propósito do trabalho - e comercializados com um valor cultural são superior ao seu valor de uso. Trata-se, segundo Marx, do valor de troca, que supóe o conceito de valor-trabalho impresso na coisa-mercadoria. O fetichismo efetiva-se como um fenómeno cujo significado é o ato subjetivo de atribuição pelos homens, de propriedades sobrenaturais aos objetos, passando, por estes, a se encantar.

Importante se faz ainda elaborar outro elemento conceitual presente na tradição teórica marxista - que é implicitamente presente nos manuscritos -, qual seja o conceito de reificação, elaborado por Lukács ${ }^{3}$, em História e Consciência de Classe. Na obra, em tela, o autor vai apresentá-lo como a possibilidade de coisificação das relações sociais pelo ato subjetivo de introjeção de uma cultura, cuja propriedade não é comum, mas privada. Tal fato vai se tornar evidente, à medida que os homens, ao tomarem posse de objeto-coisa, passam a preservá-lo como de sua propriedade; caso este seja violado, aqueles vão à instância punitiva, no sentido de recuperá-lo. Nesse sentido: "Já muitas vezes se realçou a essência da estrutura mercantil, que assenta no facto de uma ligaçáo, uma

\footnotetext{
${ }^{3}$ Georg Lukács (1989). História e Consciência de Classe - estudos de dialética marxista, Biblioteca Ciência e Sociedade. Rio de Janeiro, Elfos Editora.
} 
relaçáo entre pessoas, tomar o caracter de uma coisa, e ser, por isso, de uma 'objectividade ilusória' que, pelo seu sistema de leis próprio, aparentemente rigoroso, inteiramente fechado e racional, dissimula todo e qualquer traço da sua essência fundamental: a relação entre homens (Luckács, 1989: 97).

Nesse momento se estabelece uma coisificação das relaçóes sociais, vez que as duas categorias - objeto-coisa e convívio social - se igualam através de uma apreensão subjetiva da realidade material vivenciada pelos homens.

\section{Consideraçóes finais}

Com base em tais reflexões, é notória a íntima relação evidenciada e denunciada pelos textos de Marx - entre as quais se inscrevem os manuscritos perfazendo, justificando e, sobretudo, legitimando a vinculação efetivada entre a dimensão subjetiva e objetiva, nas atitudes, comportamentos, ideias, modos de agir e pensar da comunidade humana.

Igualmente, há de se observar - mesmo em se tratando de textos considerados na tradição materialista de análise do real - que os textos assim denominados Manuscritos Económico-Filosóficos, de Karl Marx, obedecem a uma visão dialética de interpretaçáo da realidade material, numa perspectiva dinâmica, mas, sobretudo, obedecem a uma (com)vocaçáo dialógica, à medida que se propõem anunciar a expressão da subjetividade humana, mediada por uma produção intelectual, em que estão implícitos elementos não observáveis, não experimentáveis, náo contábeis, completando de modo paradoxal a convivência dos sujeitos com seus objetos-coisas.

É essa "novidade" que também contempla a criação intelectual do autor dos manuscritos, que, num rico detalhamento das propriedades da entidade material, - o dinheiro ilustra, com maestria e autoridade - já no incansável exercício da leitura dos antecedentes do seu objeto de estudo, o capitalismo; é quando ele expóe, narra, disserta, argumenta e propóe, com rigor científico e vocação militante, uma situação concreta, real, que atinge uma paradoxal convivência trabalhador/proprietário, anunciando, dialeticamente, uma utopia 
através de cuja eleição metodológica torna-se, para ele, possível de acontecer. Eis que os Manuscritos Económico-Filosóficos vêm, enquanto notaçóes indiciais, constituir-se como prenúncios ensaísticos de uma obra que viria a consagrar Karl Marx na história da ciência e da economia política - o Capital.

\section{Bibliografia}

Bottomoore, Tom (1988). Dicionário do Pensamento Marxista. Rio de Janeiro: Jorge Zahar Editores.

Civita, Victor (1982). Para a critica de economia política: salário, preço e lucro; rendimento e suas fontes: a economia vulgar - Karl Marx. São Paulo: Abril Cultural.

Fromm, Eric (1989). Manuscritos Econômicos-Filosóficos. Lisboa: Ediçóes 70, Lda.

Lukács, Georg (1989). História e consciência de classe. Rio de Janeiro: Elfos Editora. 